\section{Análise da produção legislativa em saúde no Congresso Nacional brasileiro (1990-2006)}

\author{
Analysis of health legislation in the Brazilian \\ National Congress (1990-2006)
}

Tatiana Wargas de Faria Baptista ${ }^{1}$

\section{Introdução}

This article analyzes the submission of health policy bills by the Legislative and Executive Branches in the Brazilian National Congress, since 1990. The study analyzes the health legislation passed by the National Congress from 1990 to 2006. The bills were analyzed by type, authorship, review time, and thematic content, considering the political and institutional context. The Executive Branch passed $89.8 \%$ of its health bills, submitted budget issues and modified the approved budget, and ensured review and passage of its own bills six times faster than bills submitted by the Legislative itself. In conclusion, the policy process is imbalanced, with power concentrated in the Executive, with the latter assuming the main role of filtering health policy demands, thus reflecting a persistently immature approach for institutions in the democratic process.

Legislative Power; Executive Power; Health Policy; Health Legislation
Os estudos sobre o Poder Legislativo no que concerne o contexto de consolidação e exercício do regime democrático no Brasil tomaram vulto na década de 90 e intensificaram-se, principalmente, a partir de 2000. Diferentes aspectos relacionados ao nosso sistema político passaram a ocupar as agendas de pesquisa dos cientistas políticos, possibilitando o questionamento das regras estabelecidas na Constituição Federal de 1988 e o debate em torno das incoerências do presente modelo e da necessidade de reformulações do sistema político.

Os principais resultados dos estudos 1,2,3,4,5,6,7,8,9 indicam a existência de uma desigualdade de atuação entre os Poderes - o Poder Executivo detém a supremacia em relação às demais esferas. No âmbito Legislativo, a centralidade do Executivo expressa sua exagerada interferência no processo de produção legal e no processo de fiscalização dos seus próprios atos; além disso, sua ação também se efetiva na busca de formação de maiorias estáveis capazes de proporcionar governabilidade e aprovação de suas decisões e políticas no Congresso Nacional, estabelecendo amplas coalizões para manutenção do poder - o que Abranches denominou "Presidencialismo de Coalizão" 10. Cabe ressaltar que boa parte dessa literatura é dedicada às análises de questões da macropolítica, como as reformas constitucionais, os processos de privatizações e a 
definição do orçamento, sendo raros os estudos que aprofundam a discussão sobre uma política setorial, com exceções 11,12,13.

No debate setorial, algumas questões merecem ser exploradas, especialmente quanto ao processo político: como as demandas são encaminhadas; que grupos são mais atuantes; quais os interesses mais presentes; como e por qual razão alguns temas se transformam em leis; por que algumas leis são efetivamente implementadas e outras não. A análise desse processo pode iluminar o debate sobre a forma de atuação dos Poderes, permitindo, assim, a compreensão sobre a construção das políticas públicas e, consequentemente, dar maior transparência ao processo político e decisório. É no âmbito desta discussão que se insere este trabalho.

$\mathrm{O}$ artigo tem como objetivo analisar as atuações dos Poderes Legislativo e Executivo no Brasil, quanto à formulação de propostas políticas para a saúde no âmbito legislativo a partir do ano de 1990, sob o contexto de uma nova Carta Constitucional e, portanto, sob novas regras para o sistema político. Para tanto, identifica-se a produção legislativa em saúde aprovada pelo Congresso Nacional no período de 1990 a 2006.

O texto está organizado em quatro partes. A primeira discute as principais regras institucionais que vigoram no sistema político brasileiro e que regulam o funcionamento do Congresso Nacional a partir da Constituição de 1988. A segunda descreve a metodologia utilizada para a análise da atuação do Legislativo Federal. A terceira analisa a legislação em saúde de 1990 a 2006. Na última seção, discute-se, de forma abrangente, os resultados encontrados e as possíveis implicações para o desenvolvimento da política pública de saúde no Brasil.

\section{O sistema político brasileiro e a Constituição de 1988}

A Constituição brasileira de 1988 reafirma a separação de poderes como princípio estruturante da ordem político-institucional e coroa uma tradição de quase dois séculos, atribuindo a tal separação um caráter de imprescindibilidade para a efetivação do Estado Democrático de Direito 14. São poderes da União, independentes e harmônicos entre si: o Poder Legislativo, exercido pelo Congresso Nacional, que se compõe da Câmara dos Deputados e do Senado Federal; o Poder Executivo, exercido pelo Presidente da República, auxiliado pelos Ministros de Estado; o Poder Judiciário, exercido pelos Tribunais e Juízes Federais, dos Estados e Distrito Federal. Há, ainda, o Ministério Público, que tem por função a defesa da ordem jurídica, do regime democrático e dos interesses sociais e individuais 15 , atuando como defensor da sociedade perante os três poderes.

Com a promulgação da Constituição de 1988, o Congresso recuperou poderes subtraídos pelas sucessivas reformas constitucionais impostas pelos governos militares e autoritários, passando a contribuir de maneira mais efetiva para a formulação de políticas públicas. No entanto, a nova Carta Constitucional ainda manteve aspectos concentradores de poder no Executivo, conferindo ao Presidente da República um papel decisivo no processo legislativo. Dentre esses aspectos estão: a prerrogativa para edição de medidas provisórias (MP) com força de lei; a prerrogativa para solicitar urgência numa votação; a iniciativa de legislar em determinadas áreas; a prerrogativa de vetar, parcial ou totalmente, as leis aprovadas pelo Legislativo 2,6. Com este arranjo, o Presidente da República reúne poderes que lhe possibilitam uma influência incisiva sobre a produção legal, com poder reativo, no caso dos vetos, e poder pró-ativo, no caso da edição de MP.

Em 2001, com a aprovação da Emenda Constitucional $n^{o} .32$ (EC-32), o poder pró-ativo concedido ao Presidente na edição de MP foi regulado e sua atuação mais controlada 16. Contudo, tal medida não foi suficiente para barrar sua atuação no Poder Legislativo nos anos posteriores, seja pela manutenção de outras prerrogativas (como a solicitação de urgência na votação de seus projetos), seja, principalmente, pelo formato político-institucional no qual se sustenta o sistema político, baseado em amplas coalizões de poder.

Alguns analistas políticos 5 ressaltam que, mesmo com as mudanças introduzidas na Constituição de 1988 e com as medidas editadas subsequentemente, há ainda um longo caminho a ser trilhado no processo político-institucional, de modo a garantir a independência e harmonia entre os Poderes. Uma questão fundamental nesse caminho é a busca de um maior balanceamento de poder dentro do próprio Legislativo, que mantém um padrão altamente centralizado de organização, favorecendo o apoio legislativo à agenda Executiva em bases partidárias.

Assim, quanto à forma de organização do Congresso, cabe ressaltar que os regimentos internos da Câmara dos Deputados e do Senado Federal conferem amplos poderes aos líderes partidários para agir em nome dos interesses de seus partidos. Esses líderes exercem o controle sobre a agenda dos trabalhos, o que fornece a base para a estruturação das bancadas, garantindo a disciplina. O Poder Executivo passa a se relacionar diretamente com o Colégio de Líderes, ao qual também interessa reduzir as incertezas 
do conflito político a fim de firmar sua liderança institucional.

Há que se considerar que o formato das lideranças partidárias deveria inibir a atuação de parlamentares com interesses particulares e favorecer maior cooperação. No entanto, a atuação dos partidos e os jogos políticos que se estabelecem no sistema político brasileiro estão fundados em trocas de favores 17, o que não tem fortalecido o sistema político no sentido democrático.

Nesse contexto, deve-se considerar, ainda, a trajetória de articulação entre os Poderes no Brasil. O Executivo brasileiro se organiza em moldes muito próximos aos dos sistemas parlamentaristas, buscando apoio à sua agenda legislativa nas bases partidárias 10. Assim, o Presidente da República distribui as pastas ministeriais com o objetivo de obter o apoio da maioria dos legisladores; e os partidos que recebem as pastas são membros do governo e devem se comportar como tal no Congresso, votando a favor das iniciativas patrocinadas pelo Executivo.

Abranches 10 ressalta a especificidade do modelo brasileiro no conjunto das democracias, destacando o caráter de presidencialismo imperial aqui desenvolvido, o qual se organiza em grandes coalizões. O presidencialismo de coalizão, tal como denominado pelo autor, estaria baseado na independência dos Poderes e, principalmente, na hegemonia do Executivo, que organiza o ministério através de amplas coalizões. Essa forma de organização atende tanto aos interesses regionais (dos estados), como aos partidários, buscando maior apoio e base governista.

Essas são questões fundamentais para avançarmos na análise do modelo de relação entre o Executivo e o Legislativo na saúde, pois, como veremos, as prerrogativas do Executivo se apresentarão em algumas políticas definidas para a saúde, intermediando interesses junto aos parlamentares, bem como servindo de importante interlocutor dos movimentos sociais.

\section{Metodologia}

A análise da atuação do Legislativo Federal foi feita a partir da identificação da produção legislativa em saúde - medidas provisórias (MP), decretos (DEC), resoluções (RES), leis ordinárias e emendas constitucionais (EC) - aprovada pelo Congresso Nacional e sancionada pelo Presidente da República no período de 1990 a 2006. As matérias legislativas foram capturadas na página oficial do Senado Federal (http://www. senado.gov.br), argumento "saúde", para o período estipulado, o que compreendeu não só leis específicas da saúde, como também leis que, de alguma forma, interferem na área, mas não se restringem a ela.

Adotou-se como marco inicial o ano de 1990, quando se editaram as leis reguladoras da saúde (Leis Orgânicas $n^{\circ}$. 8080 e $n^{\circ}$. 8142). No mesmo ano, o país iniciou um novo ciclo na vida política com uma nova legislatura (49ạ), já sob as regras da nova Carta Constitucional, e com a entrada de um Presidente eleito de forma direta após mais de vinte de anos de ditadura e eleições indiretas. O término da análise no ano de 2006 justifica-se por este encerrar a 52a legislatura e por ser o último ano do primeiro mandato do Governo Lula, fechando um ciclo para análise da política.

A análise das matérias legislativas exigiu uma compreensão do papel de cada matéria (MP, DEC, RES, Lei e EC) no processo legislativo. Cada documento foi identificado por autoria, tempo de tramitação e temas contemplados, com cruzamento das informações.

A revisão bibliográfica que trata do sistema político brasileiro, da relação entre Poderes e das definições firmadas na Constituição de 1988 foi condição inicial para o estudo e oferece a fundamentação teórica à análise aqui empreendida, bem como o estudo específico da política de saúde em todo o período.

\section{Produção legislativa em saúde}

O principal objetivo desta seção é identificar até que ponto as regras institucionais do sistema político imprimem lógicas no desenvolvimento da discussão setorial da saúde e como se configurou a política de saúde no período analisado.

O mapeamento da produção legislativa revelou um universo amplo de documentos produzidos com diferentes propósitos e com alcance igualmente diferenciado. Nos 16 anos apurados, foram apresentados DEC, MP, Leis, EC e RES, num total de 914 documentos (Tabela 1).

Dos 914 documentos editados, 821 (89,8\%) foram de autoria do Executivo, havendo predomínio das matérias de sua autoria em todos os anos (Figura 1). Tal predomínio se deu especialmente nos documentos que são prerrogativas do Executivo, principalmente as MP, DEC (Tabela 1) e matérias orçamentárias (apresentadas na forma de lei, DEC ou MP) (Figura 1).

As MP são documentos criados com o objetivo de atender a necessidade do Presidente de editar medidas de caráter relevante e urgente, que se aplicam com a força da lei. No período da pesquisa, das 279 MP editadas, apenas seis foram convertidas em lei; as demais introduziram mudanças, mas não foram apreciadas pelo Congresso. Este fato significa que os Presidentes 
Produção legislativa referente ao setor da saúde no período de 1990 a 2006, Brasil.

\begin{tabular}{|c|c|c|c|c|c|c|c|c|c|}
\hline $\begin{array}{l}\text { Legislaturas/ } \\
\text { Governos }\end{array}$ & Anos & Leis & $\begin{array}{l}\text { Medidas } \\
\text { Provisórias }\end{array}$ & Decretos & $\begin{array}{c}\text { Resoluções } \\
\text { do Senado } \\
\text { Federal }\end{array}$ & $\begin{array}{l}\text { Decretos } \\
\text { Legislativos }\end{array}$ & $\begin{array}{c}\text { Emendas } \\
\text { Constitucionais }\end{array}$ & $\begin{array}{c}\text { Decretos do } \\
\text { Congresso } \\
\text { Nacional }\end{array}$ & Total \\
\hline \multicolumn{10}{|l|}{ 49ạ } \\
\hline \multirow[t]{4}{*}{ Collor } & 1990 & 4 & 3 & 42 & 2 & 0 & 0 & 0 & 51 \\
\hline & 1991 & 3 & 1 & 34 & 1 & 0 & 0 & 0 & 39 \\
\hline & 1992 & 4 & 0 & 35 & 2 & 1 & 0 & 0 & 42 \\
\hline & Subtotal & 11 & 4 & 111 & 5 & 1 & 0 & 0 & 132 \\
\hline \multirow[t]{3}{*}{ Itamar } & 1993 & 9 & 12 & 25 & 1 & 0 & 0 & 0 & 46 \\
\hline & 1994 & 6 & 12 & 18 & 3 & 0 & 0 & 0 & 39 \\
\hline & Subtotal & 14 & 24 & 43 & 4 & 0 & 0 & 0 & 85 \\
\hline \multicolumn{10}{|l|}{$50 \underline{a}$} \\
\hline \multirow[t]{4}{*}{$\mathrm{FHCl}$} & 1995 & 7 & 14 & 31 & 0 & 1 & 0 & 0 & 53 \\
\hline & 1996 & 9 & 16 & 34 & 2 & 0 & 0 & 0 & 61 \\
\hline & 1997 & 9 & 41 & 29 & 2 & 1 & 0 & 0 & 82 \\
\hline & 1998 & 9 & 27 & 22 & 2 & 0 & 0 & 0 & 60 \\
\hline \multicolumn{10}{|l|}{$51 \underline{a}$} \\
\hline \multirow[t]{5}{*}{$\mathrm{FHC} \|$} & 1999 & 9 & 55 & 24 & 1 & 0 & 0 & 0 & 89 \\
\hline & 2000 & 12 & 58 & 15 & 0 & 1 & 1 & 0 & 87 \\
\hline & 2001 & 18 & 24 & 23 & 0 & 2 & 1 & 0 & 68 \\
\hline & 2002 & 15 & 3 & 18 & 3 & 3 & 0 & 1 & 43 \\
\hline & $\begin{array}{c}\text { Subtotal (FHC } \\
\text { I + FHC II) }\end{array}$ & 88 & 238 & 196 & 10 & 8 & 2 & 1 & 543 \\
\hline \multicolumn{10}{|l|}{$52 \underline{a}$} \\
\hline \multirow[t]{5}{*}{ Lula } & 2003 & 12 & 3 & 25 & 1 & 2 & 0 & 0 & 43 \\
\hline & 2004 & 11 & 2 & 16 & 1 & 1 & 0 & 0 & 31 \\
\hline & 2005 & 11 & 1 & 13 & 0 & 1 & 0 & 1 & 27 \\
\hline & 2006 & 13 & 7 & 28 & 0 & 4 & 1 & 0 & 53 \\
\hline & Subtotal & 47 & 13 & 82 & 2 & 8 & 1 & 1 & 154 \\
\hline Total & & 160 & 279 & 432 & 21 & 17 & 3 & 2 & 914 \\
\hline
\end{tabular}

Fonte: Elaborado com base nas informações disponíveis na página de internet oficial do Senado Federal, base "Legislação Federal", argumento "saúde", para o período 1990-2006 (http://www6.senado.gov.br/sicon/PreparaFormPesquisa.action).

Nota: Uma mesma Medida Provisória pode ser apresentada várias vezes no ano. Na contagem consideramos as reedições.

têm conseguido, por intermédio das MP, legislar à margem do Congresso. É importante destacar o uso abusivo desse documento nos anos de 1997 a 2001, quando é expressiva a participação das MP na produção legal. Nesse período, duas leis da saúde estiveram sob alvo constante das medidas: a lei sobre a remoção de órgãos e tecidos (Lei $n^{o}$. 9.434/97), ao todo $33 \mathrm{MP}$, e a lei sobre a regulação dos Planos e Seguros Privados de Assistência à Saúde (Lei $n^{\circ}$. 9656/98), com 45 MP. Tal modo de atuar do Executivo sofreu uma inflexão quando se estabeleceram novas regras institucionais, no ano de 2001 (EC-32), limitando o uso da MP. Na saúde, como se vê na Tabela 1, a nova regulamentação significou a queda drástica no número de MP apresentadas.

O decreto é um documento que compete ao Poder Executivo e que funciona na regulamen- tação dos atos administrativos, como a criação de cargos, mudança de estrutura, instituição de grupos de trabalho, remanejamento de recursos orçamentários, entre outros. Pode ser entendido como um meio legal para encaminhar as políticas de governo. No período analisado, boa parte da produção legal é de decretos (47\%), os quais foram utilizados em todos os anos - o que é compatível com a natureza do documento. Ressaltese, contudo, o elevado número de DEC orçamentários apresentados em todo período, que, junto com as demais matérias orçamentárias (leis e $\mathrm{MP})$, compõem um quadro curioso que merece ser aprofundado.

As matérias orçamentárias apresentam-se constantes em toda a série histórica (Figura 1), destacando-se em alguns períodos, como nos primeiros anos da série (1990 a 1993), no período de 

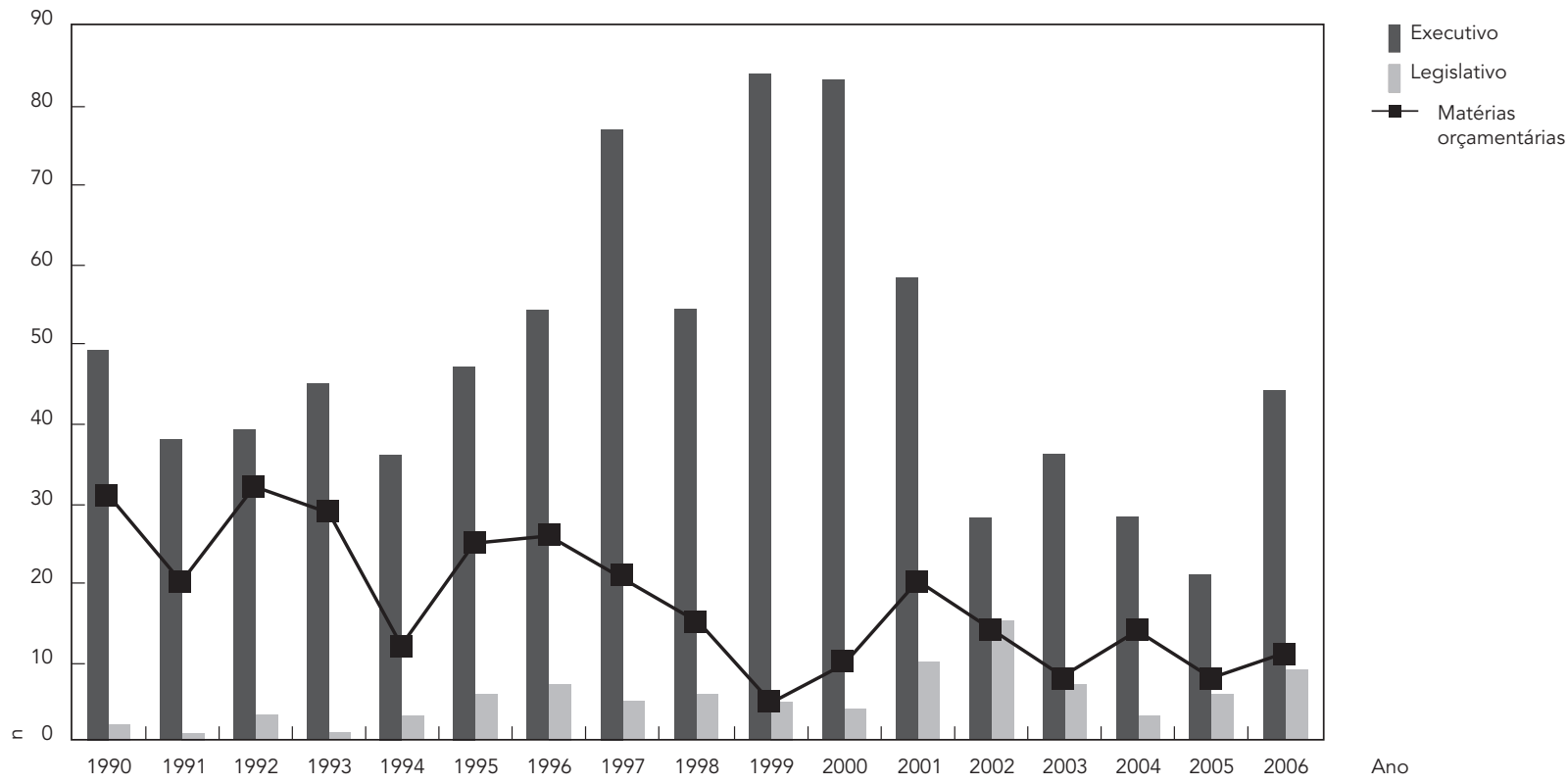

1995 a 1997 e no início dos anos 2000 (Tabela 1). As matérias orçamentárias são de iniciativa exclusiva do Poder Executivo, que pode propor a definição de créditos adicionais no Orçamento anual por meio de leis, DEC e MP. No caso das leis, novos recursos são propostos e aprovados pelo Congresso por maioria simples (créditos especiais), o que não é difícil na atual organização do sistema político; os decretos orçamentários promovem a redistribuição de recursos sem acarretar novas despesas e não requerem a aprovação do Congresso (créditos suplementares); já as MP são apresentadas em casos especiais e aprovadas em situação de urgência (créditos extraordinários). Nas três situações, há um jogo político de negociação entre o Executivo e Legislativo; este promove modificações nas dotações orçamentárias anuais com implicações pouco claras sobre o destino dos recursos. Visto que ao Executivo cabe decidir sobre a execução de um orçamento aprovado, este leva vantagens no processo por concentrar as informações sobre a disponibilidade de recursos no Tesouro Nacional 9 - fato que acarreta uma relação de desigualdade entre os Poderes. É importante destacar que o orçamento da saúde sofreu intempéries variadas durante todo o período (1990-2006), nunca tendo garantido uma fonte estável e segura de recursos, mesmo com a aprovação da Emenda Constitucional $n^{\circ} .29$ (EC-29) no ano 2000, que definiu recursos mínimos para a saúde.

Esse quadro geral demonstra, inicialmente, uma fragilidade do Legislativo em face do Executivo, corroborando a análise da literatura especializada sobre a centralidade do Poder Executivo na condução das políticas. Contudo, algumas reflexões podem se somar a essa discussão, especialmente quando o foco de análise são as leis ordinárias editadas, excluindo as leis orçamentárias.

\section{As leis da saúde}

O primeiro aspecto que se pode ressaltar a partir da análise das leis (exceto orçamentárias) é o fato de haver um maior equilíbrio na autoria delas, especialmente a partir de meados da década de 90 (Figura 2), tendo o Executivo e o Legislativo aprovado, cada um, 48 leis.

Houve variações importantes no padrão de autoria nos anos, bem como nos temas abordados pelos Poderes Executivo e Legislativo. Enquanto o primeiro buscou legislar, principalmente, políticas que se referem à administração, regula- 


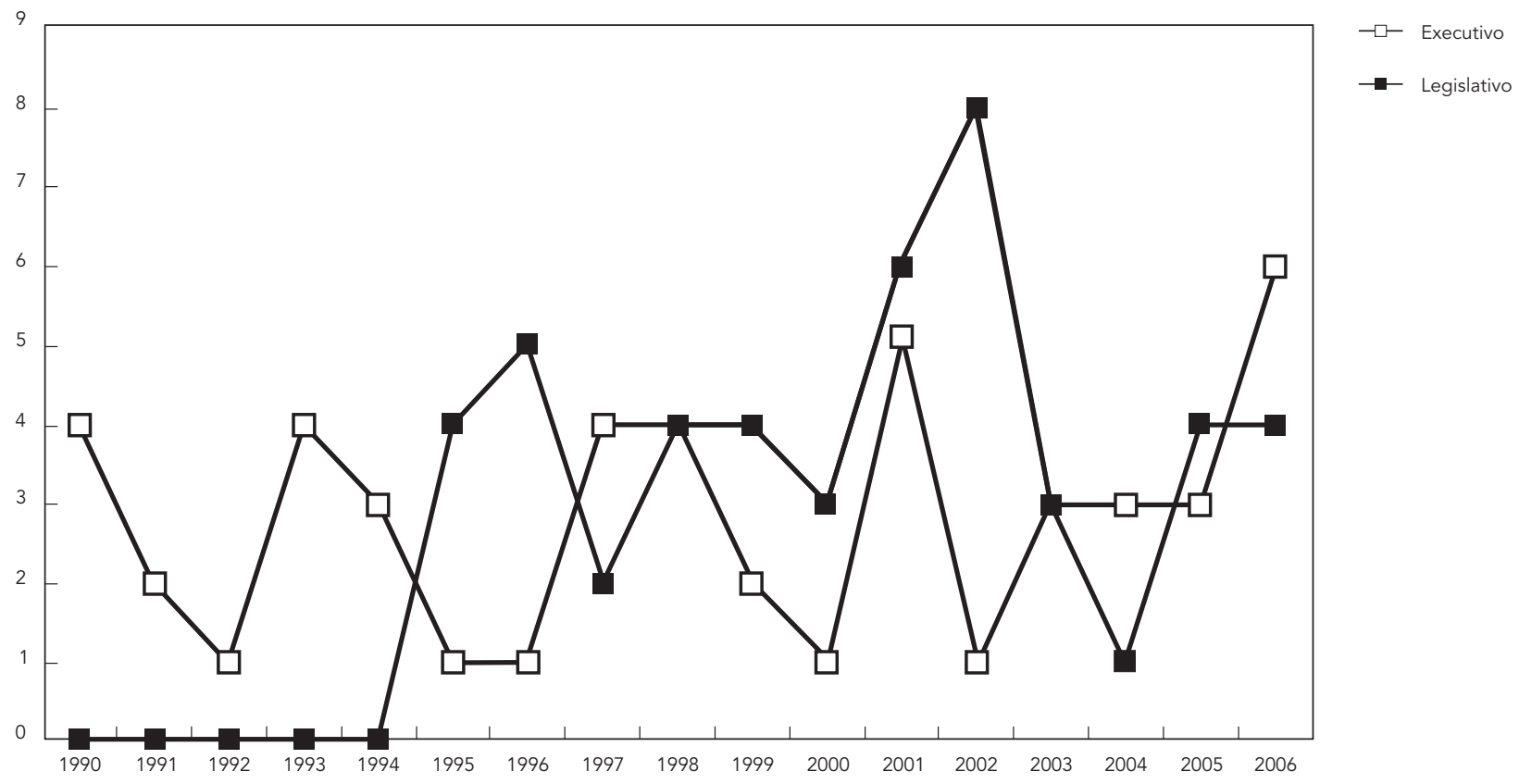

ção e organização da política setorial, o segundo buscou atender a demandas mais diversificadas e que representassem os interesses de grupos específicos, como a mulher, o índio, o portador do HIV e outros, corroborando o que diz a literatura sobre a forma de atuar do Legislativo ${ }^{18}$. Isso não significa que o Executivo não tenha recepcionado demandas sociais, embora a produção mostre que há uma divisão de atribuições na autoria das leis (Tabela 2).

Deve-se atentar para o fato de que muitas leis de autoria do Legislativo foram demandas patrocinadas pelo Executivo, como foi o caso da lei de medicamentos para a AIDS. A política de AIDS extrapolava a questão saúde e envolvia desde interesses internacionais dos governos (que exigiam respostas governamentais ao problema de saúde pública), até interesses das organizações não governamentais que atuam nessa área. Ou seja, os governos e movimentos sociais exigiam, nesse contexto, um posicionamento da Presidência para a política de AIDS. No Brasil esse posicionamento foi afirmado por um Executivo comprometido com a política de atenção universal, igualitária e integral à saúde, contando com um movimento social participativo no pro- cesso decisório 19. Foi essa composição que deu agilidade a essa política, que teve uma tramitação recorde no Congresso Nacional (90 dias).

Dessa experiência, é possível apreender que o tema e o tempo de tramitação dos projetos são variáveis importantes na análise da atuação de cada Poder. No presente estudo, verificou-se que, enquanto o Executivo levou em média 260 dias para aprovar um projeto, o Legislativo levou em média 1.501 dias - isto é, quase seis vezes mais tempo. Além disso, os projetos de lei de autoria do Legislativo que eram de interesse do Executivo tiveram tramitações mais aceleradas, ao passo que os projetos de lei de autoria do Executivo que envolveram negociações conflituosas no interior do governo foram mais lentos.

Dado o exposto, o quadro que se apresenta é o seguinte: nas leis de iniciativa do Executivo, destoam aquelas que tramitam por mais de sessenta dias (Tabela 2); entre elas estão incluídas as de maior conflito com o governo, por exemplo, a Lei $n^{\circ} .8080$ (Lei Orgânica da Saúde) e a lei de extinção do Instituto Nacional de Assistência Médica da Previdência Social (INAMPS) (Lei $n^{o}$. 8.689/93). 
Leis Ordinárias e Emendas Constitucionais da saúde aprovadas pelo Congresso Nacional no período de 1990 a 2006, Brasil.

\begin{tabular}{|c|c|c|c|c|}
\hline Leis & Ano & Autoria & $\begin{array}{l}\text { Projeto } \\
\text { de Lei }\end{array}$ & Tramitação \\
\hline Lei nº. 8.080 (Lei Orgânica da Saúde) & 1990 & Executivo * & $3.110 / 1989$ & 390 dias \\
\hline Lei $n^{\circ} .8 .142$ (Lei Complementar) & 1990 & Executivo * & $5.995 / 1990$ & 5 dias \\
\hline Lei $n^{\circ} .8 .212$ (Lei da Seguridade Social) & 1991 & Executivo & $826 / 1991$ & 21 dias \\
\hline Lei nº 8.246 (Instituição da Associação Pioneiras Sociais) & 1991 & Executivo & $1.263 / 1991$ & 117 dias \\
\hline Lei nº 8.689 (Extinção do INAMPS) & 1993 & Executivo & $3.716 / 1993$ & 90 dias \\
\hline $\begin{array}{l}\text { Lei nº. } 8.918 \text { (Padronização, classificação, registro, } \\
\text { inspeção, produção e fiscalização de bebidas) }\end{array}$ & 1994 & Executivo & $171 / 1987$ & 2.575 dias \\
\hline Lei n. 9.005 (Obriga a iodação do sal) & 1995 & Comissão mista & PLV 1/1995 & 7 dias \\
\hline Lei $n^{\circ} .9 .010$ (Terminologia hanseníase) & 1995 & Dep. Elias Murad (PSDB/MG) & $1.624 / 1991$ & 1.319 dias \\
\hline Lei n. 9.050 (Memorial da medicina brasileira) & 1995 & Dep. Eraldo Tinoco (PFL/BA) & $4.807 / 1990$ & 1.882 dias \\
\hline Lei $n^{\circ} .9 .055$ (Disciplina uso do asbesto/amianto) & 1995 & Dep. Eduardo Jorge (PT/SP) & $3.981 / 1993$ & 695 dias \\
\hline Lei $n^{\circ} .9 .263$ (Define o planejamento familiar) & 1996 & Dep. Eduardo Jorge (PT/SP) & 209/1991 & 1.700 dias \\
\hline Lei $n^{\circ} .9 .273$ (Dispositivo segurança para seringas) & 1996 & Sen. Marcio Lacerda (PMDB/MT) & 19/1991 & 1.882 dias \\
\hline $\begin{array}{l}\text { Lei } n^{\circ} .9 .294 \text { (Regula uso e propaganda de produtos } \\
\text { fumígeros, álcool, medicamentos e outros) }\end{array}$ & 1996 & Dep. Elias Murad (PSDB/MG) e outros & $4.556 / 1989$ & 2.430 dias \\
\hline Lei $n^{\circ} .9 .311$ (Institui a CPMF) & 1996 & Executivo & $2.317 / 1996$ & 60 dias \\
\hline $\begin{array}{l}\text { Lei } n^{\circ} .9 .313 \text { (Define a distribuição de medicamentos } \\
\text { para AIDS) }\end{array}$ & 1996 & Sen. José Sarney (PMDB/AP) & $158 / 1996$ & 90 dias \\
\hline $\begin{array}{l}\text { Lei n. } 9.431 \text { (Dispõe sobre o Programa de Controle } \\
\text { das Infecções Hospitalares) }\end{array}$ & 1997 & Sen. Jutahy Magalhães (PSDB/BA) & $138 / 1991$ & 2.035 dias \\
\hline $\begin{array}{l}\text { Lei } n^{\circ} .9 .434 \text { (Dispõe sobre a remoção de órgãos, tecidos e } \\
\text { partes do corpo humano) }\end{array}$ & 1997 & Sen. José Eduardo Dutra (PT/SP) & $6 / 1995$ & 730 dias \\
\hline Lei n. 9.436 (Dispõe sobre a jornada de trabalho médico) & 1997 & Executivo & $693 / 195$ & 581 dias \\
\hline $\begin{array}{l}\text { Lei n. } 9.656 \text { (Regula os planos e seguros privados de } \\
\text { saúde) }\end{array}$ & 1998 & Sen. Iram Saraiva (PMDB/GO) & 93/1993 & 1.760 dias \\
\hline $\begin{array}{l}\text { Lei } n^{\circ} .9 .782 \text { (Define o Sistema de Vigilância Sanitária e cria } \\
\text { a ANVISA) }\end{array}$ & 1999 & Executivo & $\begin{array}{c}\mathrm{MP} \\
1.791 / 1998\end{array}$ & 15 dias \\
\hline Lei nº. 9.787 (Lei dos genéricos) & 1999 & Dep. Eduardo Jorge (PT/SP) & $2.022 / 1991$ & 2.615 dias \\
\hline $\begin{array}{l}\text { Lei } n^{\circ} .9 .797 \text { (Obriga a cirurgia plástica reparadora de } \\
\text { mama no SUS) }\end{array}$ & 1999 & Dep. Maria Elvira (PMDB/MG) & $3.769 / 1997$ & 545 dias \\
\hline Lei $n^{\circ} .9 .836$ (Regula o subsistema de saúde indígena) & 1999 & Dep. Sergio Arouca (PPS/RJ) & $4.681 / 1994$ & 1.945 dias \\
\hline $\begin{array}{l}\text { Emenda Constitucional } n^{\circ} .29 \text { (Assegura recursos mínimos } \\
\text { para o financiamento das ações e serviços de saúde) }\end{array}$ & 2000 & Dep. Carlos Mosconi (PSDB/MG) & $\begin{array}{c}\text { PEC } \\
82 / 1995\end{array}$ & 1.961 dias \\
\hline Lei n. 9.961 (Cria a ANS) & 2000 & Executivo & PLV 2/2000 & 22 dias \\
\hline $\begin{array}{l}\text { Lei } n^{\circ} .9965 \text { (Restringe a venda de esteróides ou peptídeos } \\
\text { anabolizantes) }\end{array}$ & 2000 & Sen. Ney Suassuna (PMDB/PB) & $64 / 1996$ & 1.475 dias \\
\hline $\begin{array}{l}\text { Lei } n^{\circ} .10185 \text { (Sobre a especialização das sociedades } \\
\text { seguradoras em planos privados de assistência à saúde) }\end{array}$ & 2001 & Executivo & $\begin{array}{c}\text { MP } \\
2.122 / 2001\end{array}$ & 16 dias \\
\hline $\begin{array}{l}\text { Lei nº } 10191 \text { (Sobre a aquisição de produtos para } \\
\text { implementação de ações de saúde no âmbito do Ministério } \\
\text { da Saúde) }\end{array}$ & 2001 & Executivo & $\begin{array}{c}\text { MP } \\
2.070 / 2001\end{array}$ & 19 dias \\
\hline Lei $n^{\circ} .10 .216$ (Redireciona o modelo em saúde mental) & 2001 & Dep. Paulo Delgado (PT/MG) & $3.657 / 1989$ & 4.380 dias \\
\hline $\begin{array}{l}\text { Lei } n^{\circ} .10 .223 \text { (Obriga a cirurgia reparadora de mama nos } \\
\text { planos de saúde) }\end{array}$ & 2001 & Dep. Jandira Feghali (PCdoB/RJ) & $3.107 / 2000$ & 350 dias \\
\hline $\begin{array}{l}\text { Lei } n^{\circ} .10 .237 \text { (Define inserção da mensagem "sexo } \\
\text { seguro" nas fitas de vídeo) }\end{array}$ & 2001 & Dep. Fernando Rodrigues (PTB/RJ) & $1.180 / 1995$ & 2.404 dias \\
\hline $\begin{array}{l}\text { Lei } n^{\circ} .10 .273 \text { (Sobre o uso do bromato de potássio na } \\
\text { farinha e nos produtos de panificação) }\end{array}$ & 2001 & Dep. Valdeci de Oliveira (PT/RS) & $2.796 / 1997$ & 1.382 dias \\
\hline $\begin{array}{l}\text { Lei } n^{\circ} .10 .289 \text { (Estabelece o Programa de Controle do } \\
\text { Câncer de Próstata) }\end{array}$ & 2001 & Dep. Telma de Souza (PT/SP) & $3.500 / 1997$ & 1.490 dias \\
\hline
\end{tabular}

(continua) 


\begin{tabular}{|c|c|c|c|c|}
\hline Leis & Ano & Autoria & $\begin{array}{l}\text { Projeto } \\
\text { de Lei }\end{array}$ & Tramitação \\
\hline $\begin{array}{l}\text { Lei } n^{\circ} .10 .332 \text { (Institui mecanismo de financiamento para } \\
\text { o Programa de Ciência e Tecnologia, para a pesquisa em } \\
\text { saúde, genoma e outros) }\end{array}$ & 2001 & Executivo & MSG 1060 & 75 dias \\
\hline Lei n. 10.409 (Lei Antidrogas) & 2002 & Dep. Elias Murad (PSDB/MG) & $1.873 / 1991$ & 3.763 dias \\
\hline Lei no. 10.424 (Regulamenta a assistência domiciliar no SUS) & 2002 & Sen. Dr. Hélio (PDT/SP) & $667 / 1999$ & 1.095 dias \\
\hline $\begin{array}{l}\text { Lei n }{ }^{\circ} .10 .439 \text { (Define o Dia do Combate à Hipertensão } \\
\text { Arterial) }\end{array}$ & 2002 & Sen. Fernando Bezerra (PMDB/RN) & 235/1999 & 1.095 dias \\
\hline Lei $\mathrm{n}^{\circ} .10 .449$ (Dispõe sobre o comércio de preservativos) & 2002 & Dep. Maria Elvira (PMDB/MG) & $102 / 1999$ & 1.155 dias \\
\hline Lei n’. 10.456 (Define o Dia do Combate ao Glaucoma) & 2002 & Dep. Pedro Canedo (PSDB/GO) & $3.558 / 2000$ & 605 dias \\
\hline Lei n. 10.465 (Define o Dia da Saúde Bucal) & 2002 & Dep. Ricardo Ferraço (PPS/ES) & $3.088 / 2000$ & 730 dias \\
\hline $\begin{array}{l}\text { Lei no. } 10.507 \text { (Cria a profissão de agentes comunitários de } \\
\text { saúde) }\end{array}$ & 2002 & Executivo & $6.035 / 2002$ & 162 dias \\
\hline $\begin{array}{l}\text { Lei n. } 10.516 \text { (Institui a carteira nacional de saúde da } \\
\text { mulher) }\end{array}$ & 2002 & Dep. Aloysio Ferreira & $340 / 1995$ & 2.645 dias \\
\hline Lei $\mathrm{n}^{\circ} .10 .651$ (Estabelece o controle do uso da talidomida) & 2003 & Sen. Lúcio Alcântara (PSDB/CE) & $1.641 / 1999$ & 1.319 dias \\
\hline $\begin{array}{l}\text { Lei } n^{\circ} .10 .674 \text { (Obriga que os produtos alimentícios } \\
\text { comercializados informem a presença de glúten) }\end{array}$ & 2003 & Dep. Eduardo Jorge (PT/SP) & $2.233 / 1999$ & 1.247 dias \\
\hline Lei n’. 10.708 (Define o auxílio reabilitação psicossocial) & 2003 & Executivo & $1.152 / 2003$ & 82 dias \\
\hline Lei n'. 10.741 (Estatuto do idoso) & 2003 & Dep. Paulo Paim (PT/RS) & $3561 / 1997$ & 1.858 dias \\
\hline $\begin{array}{l}\text { Lei } n^{\circ} .10 .778 \text { (Define a notificação compulsória violência } \\
\text { contra a mulher) }\end{array}$ & 2003 & Dep. Socorro Gomes (PCdoB/PA) & $4.493 / 2001$ & 947 dias \\
\hline Lei $n^{\circ} .10 .850$ (Atribui competências à ANS) & 2004 & Executivo & PLV 11/04 & 99 dias \\
\hline Lei n 10.835 (Dispõe sobre a renda básica de cidadania) & 2004 & Sen. Eduardo Suplicy (PT/SP) & $266 / 2001$ & 790 dias \\
\hline $\begin{array}{l}\text { Lei n. } 10.972 \text { (Autoriza o Executivo a criar empresa pública } \\
\text { de hemoderivados e biotecnologia) }\end{array}$ & 2004 & Executivo & $2.399 / 2003$ & 107 dias \\
\hline $\begin{array}{l}\text { Lei } n^{\circ} .11 .104 \text { (Sobre a obrigatoriedade de instalação de } \\
\text { brinquedotecas nas unidades de saúde) }\end{array}$ & 2005 & Dep. Luiza Erundina (PSB/SP) & $2.987 / 1999$ & 1.943 dias \\
\hline $\begin{array}{l}\text { Lei } n^{\circ} .11 .108 \text { (Garante às parturientes o direito à presença } \\
\text { de acompanhamento durante o trabalho de parto) }\end{array}$ & 2005 & Sen. Ideli Salvatti (PT/SC) & $195 / 2003$ & 682 dias \\
\hline $\begin{array}{l}\text { Lei no. } 11.255 \text { (Diretrizes da política de preservação e } \\
\text { atenção integral à saúde da pessoa portadora de hepatite) }\end{array}$ & 2005 & Dep. Mariângela Duarte (PT/SP) & $432 / 2003$ & 1.852 dias \\
\hline $\begin{array}{l}\text { Lei n. } 11.303 \text { (Institui o Dia Nacional de Conscientização } \\
\text { sobre a Esclerose Múltipla) }\end{array}$ & 2006 & Dep. Celso Russomano (PPB/SP) & $5.788 / 2001$ & 1.623 dias \\
\hline $\begin{array}{l}\text { Lei no. } 11.347 \text { (Sobre a distribuição gratuita de } \\
\text { medicamentos e materiais necessários a sua aplicação e a } \\
\text { monitoração da glicemia capilar) }\end{array}$ & 2006 & Sen. José Eduardo Dutra (PT/SP) & $597 / 1999$ & 2.518 dias \\
\hline $\begin{array}{l}\text { Lei } n^{\circ} .11 .373 \text { (Institui o Dia Nacional de Combate a } \\
\text { Psoríase) }\end{array}$ & 2006 & Sen. Delcídio Amaral (PT/MS) & $282 / 2004$ & 784 dias \\
\hline
\end{tabular}

Fonte: Elaborado com base nas informações disponíveis na página de Internet oficial do Senado Federal, base "Legislação Federal", argumento "saúde", para o período 1990-2006 (http://www6.senado.gov.br/sicon/PreparaFormPesquisa.action).

Nota: Foram excluídas as leis externas à saúde, as que alteram leis e as reedições. Grande parte dessas leis foi de autoria do Executivo, por isso há um número menor de leis de autoria do Executivo na tabela.

ANS: Agência Nacional de Saúde Suplementar; ANVISA: Agência Nacional de Vigilância Sanitária; CPMF: Contribuição Provisória sobre a Movimentação ou Transmissão de Valores e de Créditos e Direitos de Natureza Financeira; INAMPS: Instituto Nacional de Assistência Médica da Previdência Social; MP: Medida Provisória; MSG: Mensagem; PEC: Proposta de Emenda à Constituição; PLV: Projeto de Lei de Conversão; SUS: Sistema Único de Saúde; PCdoB: Partido Comunista do Brasil; PDT: Partido Democrático Trabalhista; PFL: Partido da Frente Liberal (atual Democratas - DEM); PMDB: Partido do Movimento Democrático Brasileiro; PPB: Partido Progressista Brasileiro (atual Partido Progressista - PP); PPS: Partido Popular Socialista; PSB: Partido Socialista Brasileiro; PSDB: Partido da Social Democracia Brasileira; PT: Partido dos Trabalhadores.

* Foi considerado como autoria do Executivo porque o projeto de lei inicia-se a partir de uma mensagem presidencial e só depois é apresentado como de autoria de um parlamentar. 
Percebe-se também que uma estratégia adotada pelo Executivo para dar maior agilidade à tramitação de um projeto foi a de anteceder o processo de negociação, ou seja, ao considerar o processo de negociação de uma lei proposta pelo Executivo, antes mesmo de ela ser apresentada ao Legislativo, visualizam-se tempos de tramitação muito superiores aos que se apresentam. Como exemplo, pode-se citar a discussão em torno da criação da Contribuição Provisória sobre a Movimentação ou Transmissão de Valores e de Créditos e Direitos de Natureza Financeira (CPMF), que teve início com a entrada do Ministro Adib Jatene na Saúde, em 1995, e se configurou como projeto de lei no ano de 1996, ao ser amplamente debatido no interior do Governo, antes mesmo de ser apresentado no Plenário. Tal projeto tramitou no Congresso por sessenta dias, mas sua discussão no Executivo ultrapassou bem mais do que um ano.

A Lei $n^{o}$. 8.142/90 é outro bom exemplo. Sua discussão começou a ser travada no Executivo desde a aprovação da Lei Orgânica da Saúde, e seguiram-se três meses de negociação até a apresentação de um novo projeto de lei pelo Executivo para regular a questão da participação popular e da transferência de recursos. No Congresso, o projeto tramitou cinco dias.

O que esses exemplos indicam é uma forma de composição do processo decisório, no qual o Executivo antecede e negocia, seja com os grupos de interesses reformistas, seja com as corporações, seja com os parlamentares individualmente, seja com a burocracia técnica, quais serão as regras do jogo, garantindo a priori a aprovação de suas leis, num pacto muitas vezes pouco transparente da política desenhada. Um pacto sem registros, envolvendo negociações com parlamentares e grupos de interesse que muitas vezes não se realizariam num debate ampliado. A estratégia utilizada pelo Executivo tem sido a de apresentar um projeto cuja vitória é certa, explorando bem as janelas de oportunidade 20 da política, assim pouco se sabe dos projetos que poderiam ter sido apresentados, mas não o foram porque dado momento político não era o mais propício.

Já nas leis de iniciativa do Legislativo, o que destoa são as que tramitam por menos de mil dias (mais ou menos 33 meses) (Tabela 2), destacando-se as leis de autoria das Comissões Mistas, com tramitações recordes de dois a sete dias. Essas leis, apesar de entendidas como de autoria do Legislativo, funcionaram como leis que afirmaram decisões propostas pelo Executivo e que já eram objeto de regulamentação por meio de MP, o que justifica sua tramitação acelerada frente às demais propostas.
Da mesma forma - excluindo as leis advindas das Comissões Mistas -, as leis de autoria do Legislativo que nasceram de demandas do Executivo ou se sustentaram em movimentos sociais articulados entre o Executivo e o Legislativo tramitam mais rapidamente, como no caso da lei da AIDS (90 dias). Nessa última, fica expresso que o Executivo também é capaz de atender a demandas e processá-las em políticas, não sendo, portanto, essas funções exclusivas do Legislativo.

Essa característica do Executivo permite entendê-lo tanto como um Poder que concentra poderes, quanto um Poder que se utiliza da sua prerrogativa decisória para encaminhar políticas e dar mais agilidade ao processo político e não se engessar em longos e intermináveis processos de negociação.

Nessa questão incide um dos principais debates da Ciência Política, a capacidade do Estado de governar e de decidir políticas, sem que isso signifique desconsiderar o processo negociado com os demais Poderes, instituições governamentais e sociais. A pergunta inerente a esse debate é: em que medida a concentração de poder pode igualmente ser uma estratégia para a garantia de políticas distributivas e democráticas? Essa é a questão-chave na análise da relação ExecutivoLegislativo.

Para explorar essa questão, é pertinente olhar a produção legal considerando-se o contexto em que elas se inserem. Assim, o terceiro eixo de análise foi correlacionar a lei (tema) ao momento da política de saúde.

\section{As leis no contexto da política de saúde}

A análise da legislação de saúde vis a vis a trajetória da política permite observar algumas inflexões na trajetória da política e no padrão de relação Executivo-Legislativo na saúde. Destacam-se, pelo menos, três grandes momentos. O primeiro, de definição da base institucional do SUS (1990-1994); o segundo, de expansão de políticas técnicas e específicas de saúde, seguidas de uma política de regulação do mercado em saúde (1995-2002); o terceiro, de retorno das políticas específicas diretamente atreladas a um projeto do Governo Federal (2003-2006). Cada um desses momentos expressa um determinado contexto da política de saúde e características da relação entre os Poderes.

Os primeiros quatro anos da década de 1990 (1990-1994) foram exclusivamente de leis de autoria do Executivo, visando à regulamentação das políticas previstas na Constituição (seguridade social, saúde, educação etc.) (Tabela 2). Nesses anos, não houve a aprovação de qualquer lei de autoria do Legislativo, embora um conjunto 
expressivo de projetos de lei (PL) e de emenda constitucional (PEC) tenha sido iniciado, tratando de temas importantes para a saúde, como: o PL da reforma psiquiátrica, a PEC para garantia de recursos para saúde, o PL sobre planejamento familiar, o PL para regulamentação subsistema indígena, o PL que trata dos medicamentos genéricos.

Sobressalta nesse período a atuação de um Executivo-Presidência da República orientado pelos interesses macroeconômicos, segundo uma perspectiva liberal e contrária ao desenvolvimento da política de proteção social 21 . Foram definidas políticas que vinham de encontro às propostas constitucionais, tais como a definição de uma base legal segmentada para as áreas constituintes da Seguridade Social (saúde, previdência e assistência social), a revinculação da Previdência ao Ministério do Trabalho (1990), o descumprimento no envio de $30 \%$ dos recursos do Orçamento da Seguridade Social (OSS) para a saúde, a vinculação à Previdência das contribuições dos trabalhadores sobre a folha de salários (1992); a inclusão dos Encargos Previdenciários da União (EPU) no OSS 22,23. Medidas que reforçaram um cenário de disputa de recursos entre as áreas 22.

O Legislativo, por sua vez, exerceu importante papel na negociação das leis, atuando como intermediador de interesses da saúde, especialmente no caso da lei orgânica (Lei $n^{\circ}$. 8.080/90) que sofreu vetos pelo Presidente da República (Fernando Collor). Ressalte-se que alguns vetos nunca foram devidamente recuperados, como aqueles relativos à regulamentação do financiamento e da política de recursos humanos. Dois aspectos-chave no desenvolvimento da política de saúde.

Assim, os primeiros anos de implementação da política de saúde foram anos de disputa entre as áreas constituintes da Seguridade, mas principalmente de orientação política contrária aos interesses da proteção social. O impeachment do Presidente Collor no final do ano de 1992 e o rearranjo na correlação de forças no governo a partir de 1993 trouxeram um cenário de alento para a política, possibilitando também uma recomposição de forças na saúde, o que refletiu na produção legal nos anos seguintes.

Percebe-se que, após a definição da base institucional, há um momento de maior estabilidade política e econômica no Estado brasileiro. O sucesso do Plano Real (1994) no controle da moeda possibilitou um rearranjo político-institucional, reafirmando a perspectiva liberal 21 . As reformas constitucionais tornaram-se o ponto central da estratégia de governo, tendo sido em quase sua totalidade aprovadas pelo Congresso.
Na consolidação da proteção social e do direito à saúde, o período de 1995 a 2002 expressou uma reconfiguração dos interesses, com demandas específicas e novos problemas a serem enfrentados. O período compreende os dois mandatos do Presidente Fernando Henrique Cardoso e revela uma determinada forma de condução das políticas sociais e de saúde, em um contexto de reforma administrativa orientada para redução do tamanho do Estado e mudanças no seu papel.

$\mathrm{Na}$ análise da produção legal em saúde nesse período, é possível identificar pelo menos dois subperíodos, que coincidem com os momentos de inflexão da política de saúde governamental. O primeiro, de expansão de políticas específicas e técnicas de saúde (1995-1997), quando a orientação era de enfrentamento dos dilemas na operacionalização do SUS 24, com vistas ao desenvolvimento de políticas tecnicamente fundadas e em atenção às reivindicações de grupos ou movimentos sociais organizados; o segundo, de ênfase na regulação do mercado em saúde (19982002), seguindo a tônica do governo de "intervencionismo regulatório" do Executivo por meio das agências reguladoras 25 (Tabela 2).

Com essa análise, é possível visualizar inflexões no debate sobre o direito à saúde que deixaram marcas no processo decisório em saúde e permaneceram constantes no momento seguinte. Em linhas gerais, três tendências de abordagem do direito à saúde no âmbito das leis se firmaram a partir de 1995, expressando as contradições e dilemas na garantia do direito à saúde:

Leis que reafirmam o direito à saúde, compreendido na sua abrangência, como previsto na Constituição de 1988. É o caso das leis que avançam no controle sanitário e na produção de ambientes saudáveis (iodação do sal, controle do asbesto/amianto, uso e propaganda de fumígeros, sistema de vigilância sanitária); promovem a regulamentação de áreas estratégicas da atenção à saúde (controle das infecções hospitalares, remoção de órgãos, tecidos e partes do corpo humano); atendem a demandas de áreas específicas da atenção (planejamento familiar, subsistema indígena, modelo de atenção psiquiátrico) na maior parte das vezes fruto do debate com o movimento social e em atenção às demandas deste.

Leis que segmentam o direito à saúde, discriminando direitos para alguns grupos, como no caso da lei que garante o medicamento para a AIDS.

Leis que introduzem mudanças na concepção do direito, abarcando outras visões como a lógica do direito do consumidor. É o caso da lei de regulamentação dos planos de saúde, a lei de 
criação da Agência Nacional de Saúde Suplementar (ANS) e a lei de medicamentos genéricos.

Todas as leis avançaram na constituição do direito à saúde, mas se verifica uma mudança de ênfase sobre o que se passa a legislar, fato que também reflete o movimento do Ministério da Saúde na definição de políticas nesse período 26. Do primeiro subperíodo (1995-1997), quando efervesciam as demandas técnicas e sociais, visando ao aprimoramento do direito previsto constitucionalmente, passa-se a se enfatizar a regulação na lógica do consumidor (1998 em diante). Destaca-se também, a partir dos anos 2000, um quantitativo razoável de leis de autoria do Legislativo que instituem dias nacionais de prevenção e controle de doenças ou programas de saúde prevendo ações já realizadas no âmbito da política, como o controle do câncer de próstata. A presença dessas leis denota uma forma de atuação do Legislativo que responde aos interesses tanto de corporações, quanto de movimentos sociais, num nítido exemplo de conexão eleitoral 17 (Tabela 2).

O cenário político a partir de 2003, com o início do Governo Lula, configura por si só outro momento da política de saúde, haja vista a definição de um novo projeto de governo e mudanças no quadro ministerial. As primeiras ações mais contundentes na área da saúde se expressaram na redefinição da estrutura do Ministério da Saúde, com a criação de novas secretarias e o redesenho de funções das secretarias já existentes.

Nos anos de 2003 a 2006 são aprovadas leis (Tabela 2) que versam sobre temas específicos de políticas consideradas fundamentais no projeto de governo e que não são necessariamente demandas da saúde, como a definição do estatuto do idoso e da lei que define a notificação compulsória da violência contra a mulher. Outra lei de natureza mais abrangente e que é indicada como uma lei da saúde é a que institui a renda básica de cidadania, diretamente atrelada ao projeto de governo para redução da desigualdade. Há também a aprovação da lei que autoriza o Executivo a criar a empresa pública de hemoderivados e biotecnologia, reforçando a política de Ciência \& Tecnologia no âmbito do Governo Federal.

A curiosidade desse período reflete-se numa produção legal que não tem a especificidade da saúde, e sim a de um debate mais abrangente de política social, no qual a saúde está inserida, configurando, mais precisamente, uma mudança de tom no encaminhamento das demandas de saúde no âmbito legislativo. Essa mudança também se expressa no governo federal, haja vista a discussão sobre o uso dos recursos da saúde para o financiamento do Programa "Fome Zero" no primeiro ano de governo em 2003 e o debate sobre a definição de "ações e serviços de saúde" no âmbito da regulamentação da EC-29.

O período compreende ainda um conjunto de leis que refletem a interação com diferentes movimentos sociais e o desenvolvimento de políticas específicas, como a lei que define o auxílio reabilitação social - ponto-chave no desenvolvimento da reforma psiquiátrica; a que institui o direito à gestante ao acompanhamento no momento do parto e a que define diretrizes na atenção ao portador de hepatite. Ressalte-se a lei que dispõe sobre a distribuição gratuita de medicamentos e materiais para monitoração da glicemia capilar, que, a exemplo da lei da AIDS (1996), discrimina o acesso aos medicamentos. Persistem também as leis que instituem dias de prevenção às doenças como uma marca do período.

Atente-se para o fato de que os anos que compreendem o período do primeiro Governo Lula foram os de maior produção legislativa de autoria do Legislativo, alcançando quase $20 \%$ da produção. A Tabela 3 resume os dados aqui discutidos, indicando como os anos Collor foram

Tabela 3

Produção legislativa referente ao setor da saúde no período de 1990 a 2006, por autoria, Brasil.

\begin{tabular}{|c|c|c|c|c|c|c|}
\hline Anos & Legislaturas & Governos & Executivo & $\%$ & Legislativo & $\%$ \\
\hline 1990-1992 & 49ạ & Collor & 126 & 95,3 & 6 & 4,7 \\
\hline 1993-1994 & 49ạ & Itamar & 81 & 95,1 & 4 & 4,9 \\
\hline 1995-1998 & $50 \underline{a}$ & $\mathrm{FHCl}$ & 232 & 89,7 & 24 & 10,3 \\
\hline 1999-2002 & $51 \underline{a}$ & $\mathrm{FHC} \|$ & 253 & 86,6 & 34 & 13,4 \\
\hline $2003-2006$ & $52 \underline{a}$ & Lula & 129 & 80,6 & 25 & 19,4 \\
\hline Total & & & 821 & 89,8 & 93 & 10,2 \\
\hline
\end{tabular}

Fonte: Elaborado com base nas informações disponíveis na página de Internet oficial do Senado Federal, base "Legislação

Federal", argumento "saúde", para o período 1990-2006 (http://www6.senado.gov.br/sicon/PreparaFormPesquisa.action). 
de grande produção do Executivo, com tendência à mudança nos governos Fernando Henrique Cardoso, fechando um ciclo de maior atuação do Legislativo no Governo Lula.

\section{Considerações finais}

Neste artigo, analisou-se a produção legislativa em saúde aprovada no período de 1990 a 2006 e evidenciou-se que o Poder Executivo exerce um papel preponderante na definição das propostas políticas nessa área, utilizando-se de múltiplas estratégias para exercer seu poder.

O Executivo aprovou 89,8\% das matérias legislativas em saúde no período, sendo a grande maioria de matérias de sua prerrogativa (MP, DEC). Por meio das MP legislou à margem do Congresso, editando e reeditando medidas com força de lei, acabando por modificar a implementação de leis já aprovadas, com apenas seis das 279 MP editadas apreciadas pelo Congresso. Por intermédio das MP, DEC e Leis editou matérias orçamentárias, modificando o orçamento aprovado pelo Congresso e o destino de recursos da saúde. Nas leis ordinárias (exceto as orçamentárias), garantiu um tempo de tramitação para matérias de sua autoria seis vezes mais acelerado do que nas matérias de autoria do Legislativo e imprimiu negociações prévias ao debate legislativo para garantir o trâmite acelerado de suas propostas. Nas matérias de autoria Legislativa de seu interesse, o Executivo apoiou e constituiu meios para uma tramitação acelerada no momento mais propício, intermediando os interes- ses no interior do governo e junto aos movimentos sociais, garantindo o sucesso da proposta. As propostas de autoria do Legislativo, quando não encontraram respaldo no Executivo, seguiram trâmites mais lentos e estiveram pautadas pela agenda Executiva. É imprescindível ressaltar que a agenda Executiva que prevaleceu não foi necessariamente a do Ministério da Saúde, mas a da Presidência da República.

Dessa forma, as leis aprovadas refletem muito bem os diferentes momentos de construção da política de saúde, evidenciando um padrão de relação que, embora fosse bastante harmonioso entre os Poderes, não era necessariamente equilibrado - prevalecendo a direcionalidade do projeto Executivo. Da configuração de uma base institucional-legal, passando pela definição de políticas técnicas e políticas específicas de saúde, da montagem de um intervencionismo regulatório até a configuração de políticas que atendem aos grupos marginalizados, as leis aprovadas em nada diferem dos movimentos traçados no âmbito da política de saúde.

Por fim, os dados apresentados remetem à necessidade de estudos mais detalhados sobre a relação entre Poderes na saúde, de modo a melhor compreender a dinâmica do processo decisório e de definição de prioridades. A partir disso, pode-se extrair que o processo político encontra-se desbalanceado, com um Executivo que concentra poder no âmbito do Congresso Nacional e que assume o papel principal de filtro das demandas políticas propostas para a saúde, refletindo uma forma ainda pouco madura das instituições no processo democrático.

\section{Resumo}

O artigo analisa as atuações dos Poderes Legislativo e Executivo no Brasil quanto à formulação de propostas políticas para a saúde, no âmbito legislativo, a partir do ano de 1990. Para tanto, identifica-se a produção legislativa em saúde aprovada pelo Congresso Nacional no período de 1990 a 2006. Os documentos foram analisados por tipo, autoria, tempo de tramitação e temática, considerando o contexto político-institucional. O estudo mostra que o Poder Executivo aprovou 89,8\% das matérias em saúde, editou matérias orçamentárias, modificando o orçamento aprovado, e ga- rantiu um tempo de tramitação para matérias de sua autoria seis vezes mais acelerado do que nas matérias de autoria do Legislativo. Conclui-se que o processo político encontra-se desbalanceado, com um Executivo que concentra poder e que assume o papel principal de filtro das demandas políticas propostas para a saúde, refletindo uma forma ainda pouco madura das instituições no processo democrático.

Poder Legislativo; Poder Executivo; Política de Saúde; Legislação Sanitária 


\section{Referências}

1. Santos MHC. Governabilidade, governança e de mocracia: criação de capacidade governativa e relações executivo-legislativo no Brasil pós-constituinte. Dados Rev Ciênc Sociais 1997; 30:335-76.

2. Figueiredo AC, Limongi F. Executivo e Legislativo na nova ordem constitucional. Rio de Janeiro: Fundação Getulio Vargas; 1999.

3. Figueiredo AC. Instituições e política no controle do Executivo. Dados Rev Ciênc Sociais 2001; 44:689-727.

4. Pessanha C. Relações entre os Poderes Executivo e Legislativo no Brasil: 1946-1994 [Tese de Doutorado]. São Paulo: Faculdade de Filosofia, Letras e Ciências Humanas, Universidade de São Paulo; 1997.

5. Diniz E. Relações executivo-legislativo. Grupo de Conjuntura 1995; 51:1-6.

6. Amorim Neto O. O Poder Executivo, centro de gravidade do sistema político brasileiro. In: Avelar L, Cintra AO, organizadores. Sistema Político Brasileiro: uma introdução. Rio de Janeiro/São Paulo: Fundação Konrad-Adenauer-Stiftung/Fundação Unesp; 2004. p. 123-33.

7. Amorim Neto O, Santos F. A produção legislativa do Congresso: entre a paróquia e a nação. In: Vianna LW, organizador. A democracia e os três poderes no Brasil. Belo Horizonte: Universidade Federal de Minas Gerais/Rio de Janeiro: Instituto Universitário de Pesquisas do Rio de Janeiro; 2002. p. 91-139.

8. Pereira C, Mueller B. Uma teoria da preponderância do Poder Executivo. O sistema de comissões no Legislativo brasileiro. Rev Bras Ciênc Soc 2000; 15:45-67.

9. Pereira C, Mueller B. Comportamento estratégico em presidencialismo de coalizão: as relações entre Executivo e Legislativo na elaboração do orçamento brasileiro. Dados Rev Ciênc Sociais 2002; 45:265-301.

10. Abranches S. Presidencialismo de coalizão: o dilema institucional brasileiro. Dados Rev Ciênc Sociais 1988; 31:5-34.

11. Rodrigues MMA, Zauli EM. Presidentes e Congresso Nacional no processo decisório da política de saúde no Brasil Democrático (1985-1998). Dados Rev Ciênc Sociais 2002; 45:387-429.

12. Pereira C. A política pública como Caixa de Pandora: organização de interesses, processo decisório e efeitos perversos na Reforma Sanitária brasileira 1985-1989. Dados Rev Ciênc Sociais 1996; 3: 423-78.
13. Baptista TWF. Políticas de saúde no pós-constituinte: um estudo da política implementada a partir da produção normativa dos Poderes Executivo e Legislativo no Brasil [Tese de Doutorado]. Rio de Janeiro: Instituto de Medicina Social, Universidade do Estado do Rio de Janeiro; 2003.

14. Moraes F. Executivo e Legislativo no Brasil pósConstituinte. São Paulo Perspect 2001; 15:45-52.

15. Brasil. Constituição da República Federativa do Brasil. Brasília: Congresso Nacional; 1988.

16. Brasil. Emenda Constitucional nº. 32. Diário Oficial da União 2001; 12 set.

17. Carvalho NR. E no início eram as bases: geografia política do voto e comportamento legislativo no Brasil. Rio de Janeiro: Editora Revan; 2003.

18. Mayhew DR. Congress: the electoral connection. New Haven: Yale University Press; 1974.

19. Mattos RA, Terto Jr. V, Parker R. As estratégias do Banco Mundial e a resposta à AIDS no Brasil. In: Barros F, Mineiro AS, organizadores. As estratégias dos bancos multilaterais para o Brasil. Brasília: Rede Brasil; 2001; p. 107-30.

20. Kingdom J. Agendas, alternatives and public choices. Boston: Little Brown; 1984.

21. Sallum Jr. B. Crise, democratização e liberalização no Brasil. In: Sallum Jr. B, organizadores. Brasil e Argentina hoje: política e economia. São Paulo: Edusc; 2004. p. 47-77.

22. Baptista TWF. Seguridade social no Brasil. Revista do Serviço Público 1998; 49:99-118.

23. Dain S. O financiamento público na perspectiva da política social. Economia e Sociedade 2001; 17:113-40.

24. Levcovtiz E. Transição e consolidação: o dilema estratégico da construção do SUS. Um estudo sobre as reformas da política nacional de saúde [Tese de Doutorado]. Rio de Janeiro: Instituto de Medicina Social, Universidade do Estado do Rio de Janeiro; 1997.

25. Boschi R, Lima MRS. O Executivo e a construção do Estado no Brasil: do desmonte da era Vargas ao novo intervencionismo regulatório. In: Vianna LW, organizador. A democracia e os três poderes no Brasil. Belo Horizonte: Universidade Federal de Minas Gerais/Rio de Janeiro: Instituto Universitário de Pesquisas do Rio de Janeiro; 2002. p. 195-253.

26. Machado CV. Direito universal, política nacional: o papel do Ministério da Saúde na política de saúde brasileira de 1990 a 2002. Rio de Janeiro: Editora do Museu da República; 2007.

Recebido em 26/Mar/2009

Versão final reapresentada em 27/Set/2009

Aprovado em 13/Out/2009 